\title{
PERANCANGAN SISTEM APLIKASI PENJUALAN SPAREPART PADA TOKO KIM JAYA MOTOR
}

\author{
Denni Marsudi ${ }^{1}$, Abdul Mufti ${ }^{2}$, Mei Lestari $^{3}$ \\ Program Studi Informatika, Fakultas Teknik dan Ilmu Komputer, Universitas Indraprasta PGRI \\ Jalan Raya Tengah No 80, Kelurahan Gedong, Pasar Rebo, Jakarta Timur \\ mdenni2612@gmail.com¹, abdul.mufti@gmail.com², mei_lestari@unindra.ac.id ${ }^{3}$
}

\begin{abstract}
Abstrak
Tujuan penelitian adalah untuk mempermudah dalam mengelola data penjualan Toko Kim Jaya Motor sehingga menjadi lebih efektif dan efisien karena dapat membantu menyelesaikan permasalahan pekerjaan yang berkenaan dengan pengelolaan data penjualan. Metode penelitian yang digunakan dalam analisa dan perancangan sistem penjualan berbasis java ini adalah deskriptif kualitatif yaitu dengan pengamatan langsung, wawancara dengan pihak terkait dan juga dengan melakukan dokumentasi untuk mendapatkan informasi yang dibutuhkan. Selain itu peneliti juga melakukan penelitian dengan metode kepustakaan berdasarkan referensi dan berbagai diskusi serta dari berbagai media yang memuat informasi yang dibutuhkan, menganalisa kebutuhan, perancangan, implementasi dan pengkodean, dan pengujian. Hasil dari penelitian ini adalah sistem terkomputerisasi yang dapat mempermudah karyawan toko dalam melakukan transaksi penjualan.
\end{abstract}

Kata Kunci: penjualan sparepart, java, kim jaya motor

\begin{abstract}
The purpose of research is to make it easier to manage the sales data of the Kim Jaya Motor store so that it becomes more effective and efficient as it can help solve the job problems related to the management of sales data. The research method used in the analysis and design of Java-based sales system is a qualitative descriptive that is with direct observation, interviews with related parties and also by conducting documentation to get the information needed. In addition, researchers also conduct research with literature methods based on references and various discussions as well as from various media that contain the necessary information, analyze needs, design, implementation and coding, and testing. The result of this research is a computerized system that can facilitate the store's employees in conducting sales transactions.
\end{abstract}

Keyword: spare parts sales, java, kim jaya motor

\section{PENDAHULUAN}

Perkembagan teknologi informasi pada era globalisasi sekarang ini berkembang semakin cepat gabungan dari tehnologi dan informasi dapat menghasilkan suatu sistem aplikasi. Sistem adalah sekumpulan elemen yang saling terkait atau terpadu yang dimaksdukan untuk mencapai tujuan ( Kadir, 2014), sedangkan Aplikasi adalah alat terapan yang difungsikan secara khusus dan terpadu sesuai kemampuan yang dimilikinya (Sutabri, 2012). Salah satu jenis usaha dibidang penjualan sparepart motor sangat memerlukan adanya sistem aplikasi pengolahan data untuk mempermudah dan memperlancar kinerja penjualannya, sekarang ini masih banyak pencatatan data-data penjualan yang dilakukan secara konvesional dengan dengan buku dan kalkulator, baik itu transaksi ataupun pembuatan laporan sehingga membuat kinerja toko menjadi kurang efektif dan efisien, maka dari itu peneliti ingin membuat perancangan sistem aplikasi penjualan. Perancangan adalah proses pengembangan spesifikasi baru berdasarkan rekomendasi hasil analisa sistem (Sutabri, 2012).

Berdasarkan latar belakang diatas, maka rumusan masalahnya adalah bagaimana mengatasi kesulitan dalam mengontrol stok sparepart yang ada di toko, bagaimana mengatasi kesulitan dalam menangani sparepart yang rusak, bagaimana mengatasi kesulitan dalam membuat laporan, bagaimana mengefisienkan proses transaksi penjualan, bagaimana membuat program aplikasi yang mampu melakukan proses pencatatan yang masih manual menjadi terkomputerisasi tanpa mengunakan kalkulator sebagai alat penghitung. Sedangkan tujuan dari penelitian ini adalah membuat sistem aplikasi penjualan sparepart motor pada Toko Kim Jaya Motor, untuk menghasilkan sistem yang berbasis java serta memudahkan karyawan dalam melakukan transaksi 
penjualan, memberikan kemudahan dalam mengatur penjualan toko terutama dalam hal pencatatan transaksi penjualan sparepart dan pembuatan laporan pada toko Kim Jaya Motor.

Manfaat yang didapat dari hasil penelitian ini adalah mempermudah dalam melakukan transaksi penjualan yang dapat digunakan untuk pencatatan transaksi penjualan sparepart dikomputer, membantu dalam membuat laporan sparepart agar lebih efektif dan efisien, menghasilkan sistem yang berbasis komputer serta memudahkan karyawan toko dalam melakukan pencatatan transaksi.

\section{PENELITIAN RELEVAN}

Penelitian relevan merupakan penelitian terdahulu atau sebelumnya yang relevan dengan konsep penelitian sehingga menjadi acuan atau dasar mengembangkan suatu hasil penelitian sebelumnya. Berikut peneliti mengambil sumber dari jurnal Wahyu Dwi Ananto, Bambang Eka Purnama, Indah Uly Wardati dengan nomor ISSN 2302-5700, pada tahun 2013 yang berjudul "Pembangunan Sistem Informasi Penjualan Pada Toko Ikhtiyar Audio Pacitan" dimana dalam jurnalnya sistem penjualan yang dilakukan masih konvesional dengan proses manual, hal tersebut kurang efektif untuk proses transaksinya. Dilaksanakannya penelitian bertujuan untuk membuat sistem informasi penjualan berbasis java untuk memberikan kemudahan karyawan toko dalam mencari dan mengelola data-data penjualan agar lebih akurat.(Ananto, 2013)

\section{METODE PENELITIAN}

Metode penelitian yang digunakan adalah metode deskriptif kualitatif yaitu suatu bentuk penelitian yang bertujuan untuk memberikan gambaran sistematik dan akurat mengenai fakta, sifat dan hubungan antara fenomena yang diteliti dan berusaha untuk menekankan pada pemecahan masalah aktual dengan cara mengumpulkan, menyajikan, atau menginterpretasikan serta menganalisis data dan informasi yang relevan untuk memberikan gambaran yang cukup jelas atas objek penelitian kemudian menarik kesimpulan dari keadaan yang ada pada Toko Kim Jaya Motor. Adapun cara pengumpulan data penelitian ini antara lain :

a. Studi Pustaka

Pengumpulan data dan informasi diambil dari kutipan-kutipan buku di perpustakaan, dari bahan-bahan tersebut diambil teori-teori yang dapat dijadikan landasan untuk menganalisa masalah yang dikemukankan dalam penelitian.

b. Studi Lapangan

Studi lapangan ini peneliti lakukan untuk mengamati secara langsung terhadap penerapan sistem aplikasi penjualan sparepart. Dalam studi lapangan ini digunakan teknik pengumpulan data observasi yaitu mengamati langsung proses yang berjalan dan wawancara yaitu bertanya langsung kepada pelaksana yang terlibat langsung dalam kegiatan.

c. Sumber Data

Data dan informasi yang diperoleh untuk menguatkan penelitian ini diambil dari dua sumber yaitu sumber data primer yang diperoleh.

Sedangkan untuk pengembangan penelitian ini menggunakan metode waterfall dengan langkahlangkah sebagai berikut:

a. Menentukan Syarat-syarat Informasi

Dengan menentukan serta memeriksa data, melakukan wawancara (interview) dan mengamati kegiatan penjualan yang terjadi pada Toko Kim Jaya Motor.

b. Analisa Kebutuhan

Analisa ini dibutuhkan untuk mengetahui apa saja yang dibutuhkan, bagaimana arus diagram aliran data dalam pembuatan sistem dan perancangan sistemnya, meliputi : analisa aturan bisnis sistem, analisa masukan, diagram konteks, kamus data, sistem, normalisasi yang dilakukan, format masukan dan format keluaran.

c. Perancangan Sistem

Perancangan sistem bertujuan untuk merancang sistem yang akan dibuat agar dapat diimplementasikan dengan pengguna.

d. Implementasi dan Pengkodean

Implementasi adalah proses menterjemahkan dokumen hasil desain menjadi baris-baris perintah bahasa pemrograman komputer. Semakin baik hasil analisis dan desain yang dilakukan, maka proses pengkodean ini akan lebih mudah dilakukan. 
e. Pengujian

Pengujian adalah proses untuk memastikan apakah semua fungsi sistem bekerja dengan baik dan mencari apakah masih ada kesalahan pada sistem. Pengujian sangat penting dilakukan untuk menjamin kualitas software dan juga menjadi peninjuan terakhir terhadap spesifikasi desain dan pengkodean.

\section{HASIL DAN PEMBAHASAN}

Data Flow Diagram atau dalam bahasa Indonesia menjadi Diagram Alir Data (DAD) adalah refresentasi grafik yang menggambarkan aliran informasi dan transformasi informasi yang diaplikasikan sebagai data yang mengatur dari masukan (input) dan keluaran (output).(Sukamto \& Shalahudin, 2014)

Berikut diagram alir data sistem berjalan dalam diagram konteks :

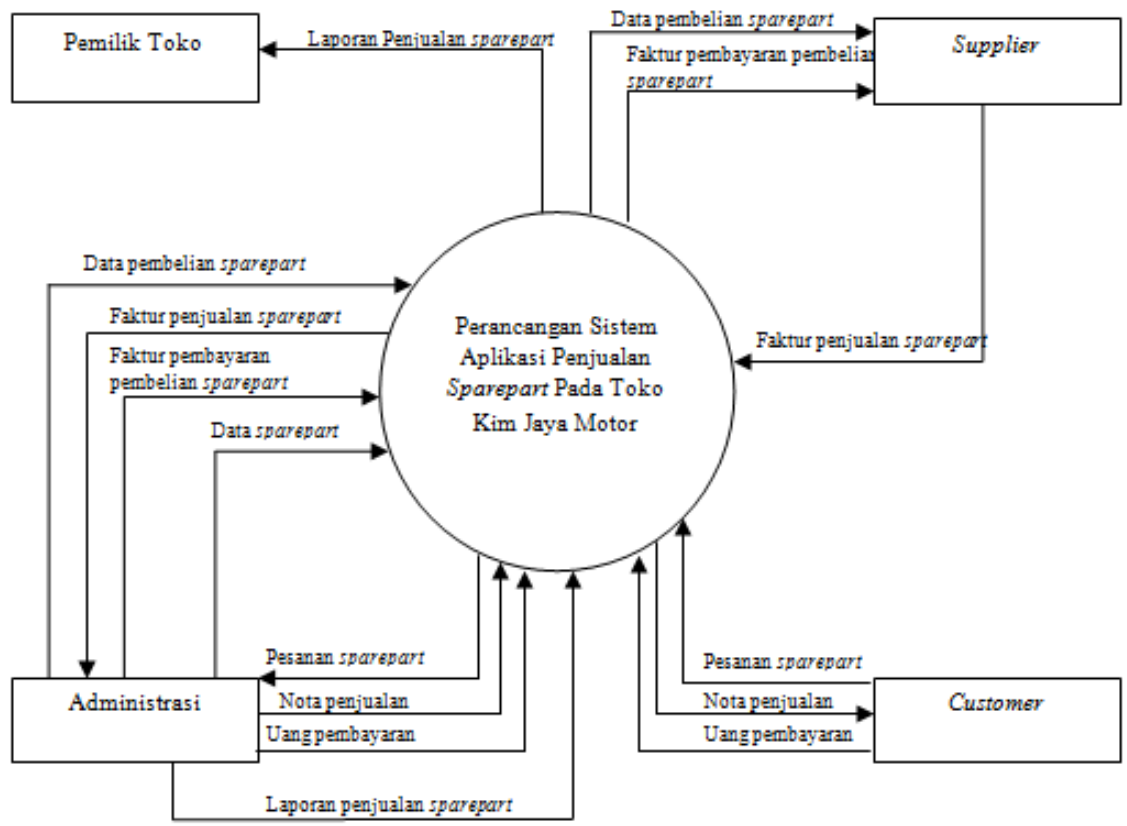

Gambar 1. Diagram Konteks Sistem Berjalan

Analisis permasalahan yang dapat disimpulkan dari hasil penelitian pada Toko Kim Jaya Motor bahwa usaha ini masih mengunakan sistem masukan data yang masih sederhana atau manual, kurangnya efisiensi waktu dalam pengerjaan laporan dikarenakan lamanya pencarian data di dalam arsip atau buku catatan, kesalahan data dalam perhitungan dan pembuatan nota membuat kurang efektifnya proses transaksi karena semua dibuat dengan manual, dan data laporan dari segi informasi yang disajikan kurang lengkap.

Alternatif penyelesaian masalah yang peneliti usulkan dengan menambah sistem aplikasi yang mudah dimengerti dan dioperasikan oleh administrasi, yaitu merancang sistem aplikasi penjualan yang mendukung proses perhitungan agar proses penjualan dapat dilakukan dengan cepat dan akurat, membuat database yang sistematis sehingga memudahkan dalam pencarian data yang dibutuhkan dalam pembuatan laporan, membuat aplikasi dengan semaksimal mungkin untuk mengurangi kesalahan atau kehilangan data, membuat aplikasi yang dapat menampilkan informasi secara lengkap menggunakan bahasa pemrograman Java. Dengan perancangan sistem aplikasi penjualan ini diharapkan dapat mempermudah proses pengolahan data laporan setiap bulannya, dan sebagai informasi yang dapat dijadikan bahan pertimbangan guna menunjang pengambilan keputusan untuk tujuan yang lebih baik.

Berikut ini adalah Gambaran sistem yang diusulkan untuk Toko Kim Jaya Motor secara keseluruhan dalam diagram konteks dan Entity Relationship Diagram (ERD). 


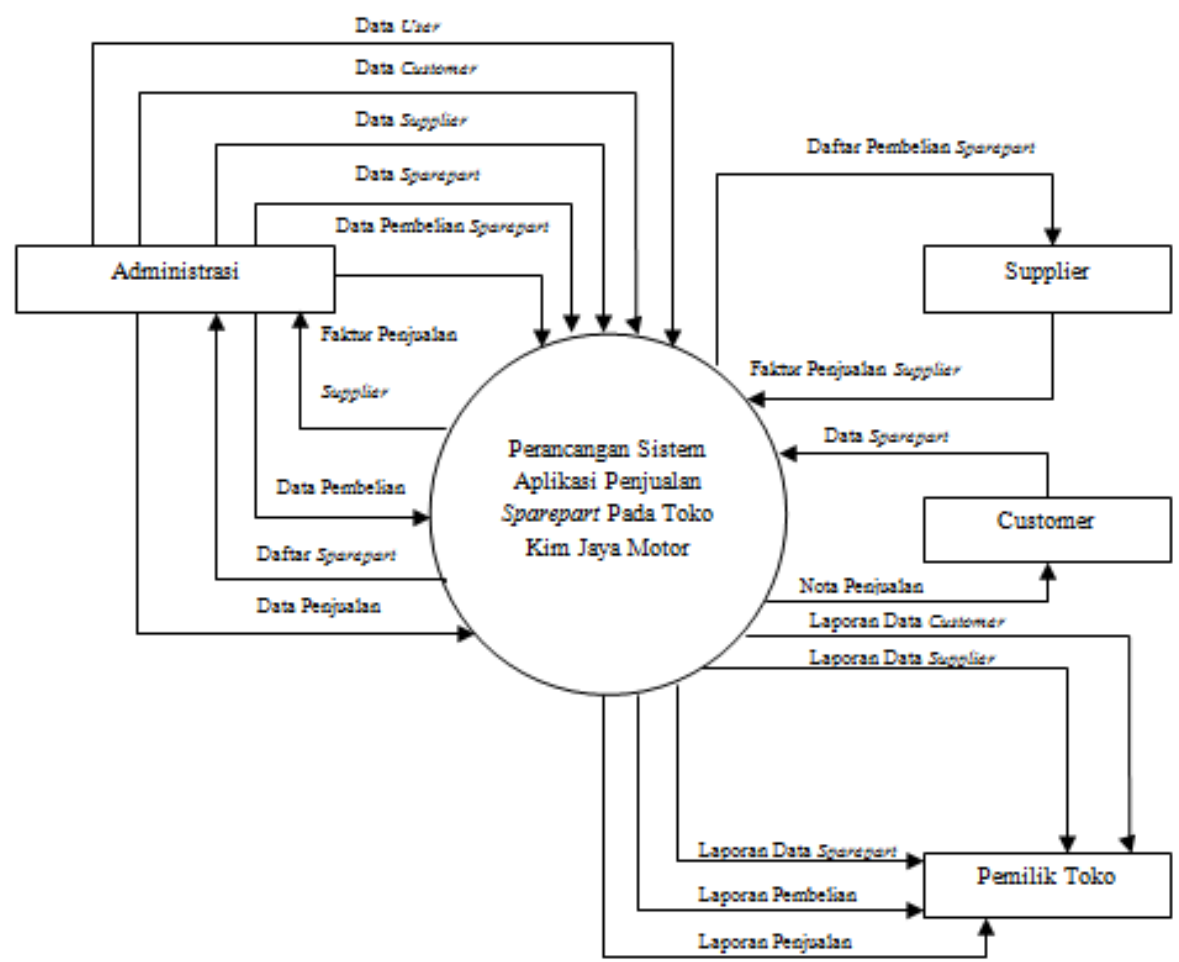

Gambar 2. Diagram Konteks Sistem yang Diusulkan

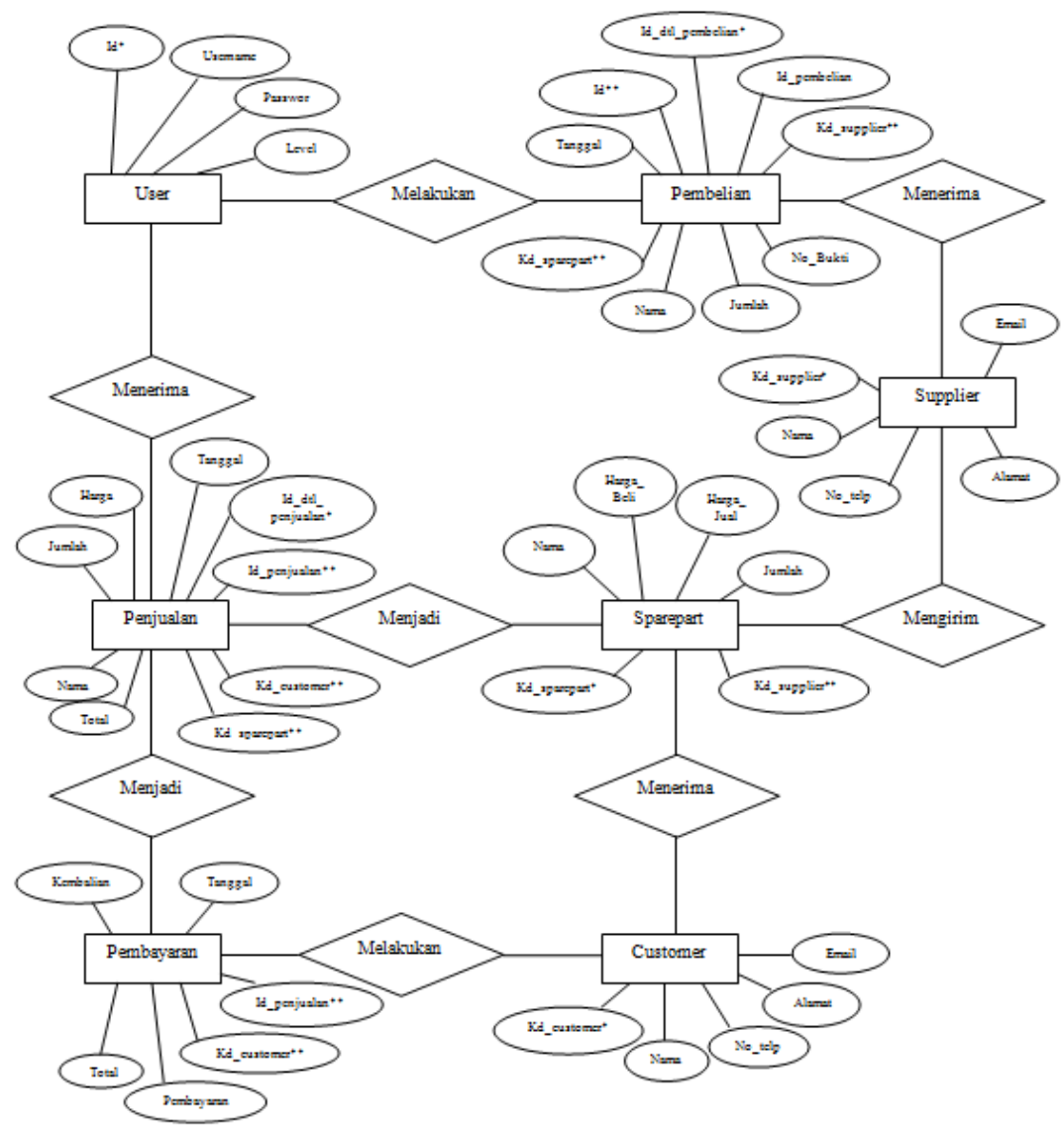

Gambar 3. Entity Relationship Diagram (ERD) 
Peneliti membuat aplikasi ini dengan menggunakan java netbeans edisi 8.2 dengan database MySQL aplikasi Xampp. Berikut tampilan dari aplikasi pada Toko Kim Jaya Motor.

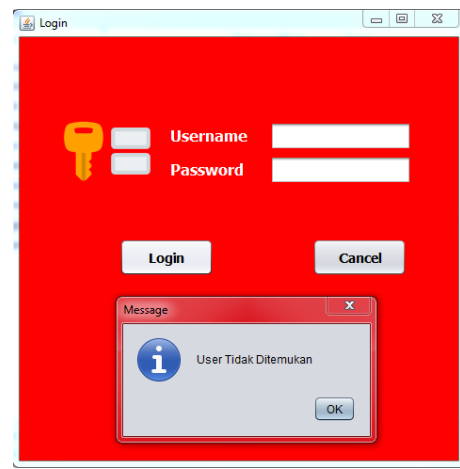

Gambar 4. Tampilan Layar Login

Tampilan layar login terdiri dari menu username, password, cancel dan login. Apabila karyawan ini masuk ke dalam aplikasi, harus memasukan username dan password lalu klik tombol login.

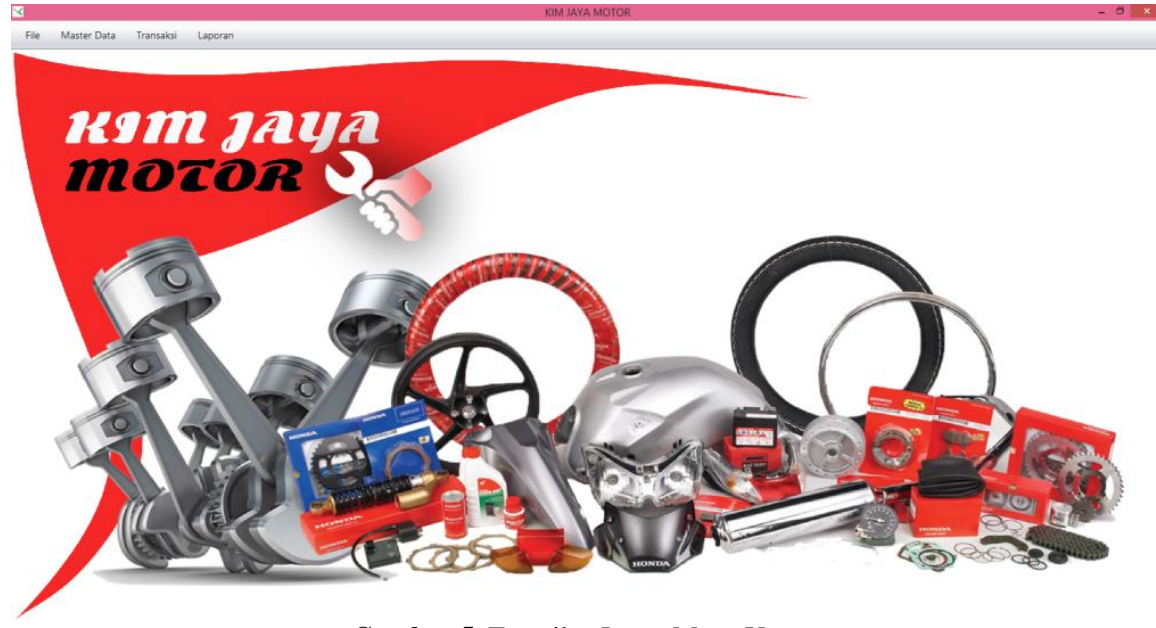

Gambar 5. Tampilan Layar Menu Utama

Jika berhasil login, maka user akan masuk ke menu utama yang terdiri dari :

a. Menu File, dalam menu ini terdiri dari sub menu logout

b. Menu Master Data, dalam menu ini terdiri dari beberapa sub menu masukan yang berfungsi sebagai data awal. Dalam menu ini terdiri dari :

1. Data Sparepart, berisi data stok barang yang ada dan akan masuk database.

2. Data Customer, berisi data customer yang membeli di toko untuk dimasukan ke database.

3. Data Supplier, berisi data supplier yang menjual barang ke toko untuk dimasukan ke database.

4. Data User, berisi data untuk membuat username dan password serta jabatan atau nama pengguna.

c. Menu Transaksi, dalam menu ini terdiri dari dua sub menu, yaitu :

1. Transaksi Pembelian, berisi data barang yang akan dibeli dari supplier seperti id pembelian, nama supplier, jumlah barang, nama barang, dan keterangan.

2. Transaksi Penjualan, berisi data barang yang akan dijual ke customer seperti id penjualan, nama customer, jumlah barang, nama barang, harga satuan dan jumlah bayar yang dapat dicetak / menghasilkan nota penjualan untuk diberikan ke customer.

d. Menu Laporan, dalam menu ini terdiri dari beberapa sub menu keluaran, yaitu :

1. Laporan Data Customer, berisi rekap data customer yang dapat dicetak.

2. Laporan Data Supplier, berisi rekap data supplier yang dapat dicetak. 
3. Laporan Data Stok Sparepart, berisi rekap data stok barang yang dapat dicetak sesuai dengan periode rekapnya.

4. Laporan Pembelian, berisi rekap pembelian barang yang dapat dicetak sesuai dengan periode rekapnya.

5. Laporan Penjualan, berisi rekap penjualan barang yang dapat dicetak sesuai dengan periode rekapnya.

Berikut ini adalah hasil keluaran (printout) yang nanti hasilnya dapat menjadi laporan manual kepada pemilik toko:

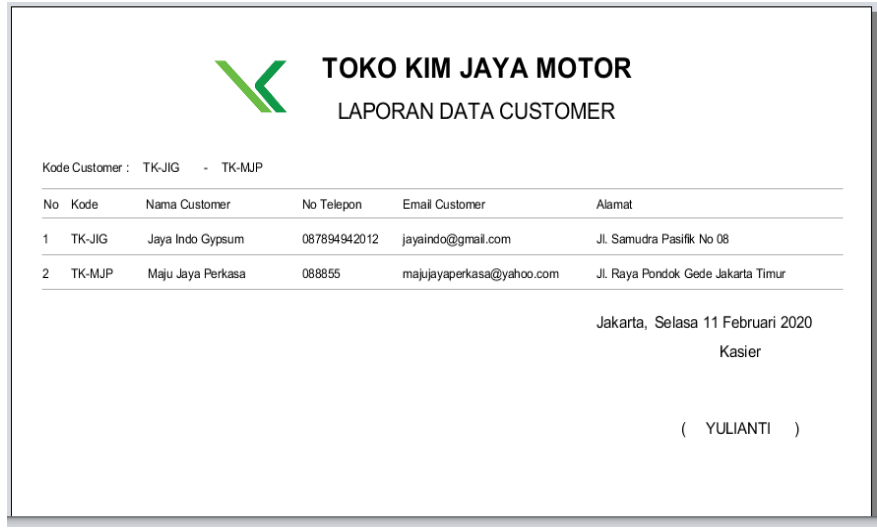

Gambar 6. Tampilan Laporan Data Customer

Laporan data customer ini didapat dari data-data customer yang sudah diinput admin ke dalam database yang nantinya diserahkan kepada pemilik toko.

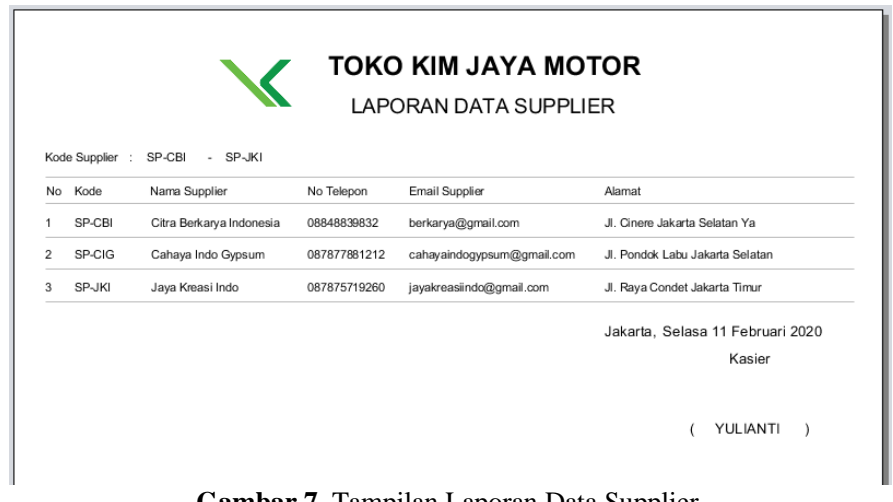

Gambar 7. Tampilan Laporan Data Supplier

Laporan data supplier ini didapat dari data-data supplier yang sudah diinput admin ke dalam database yang nantinya diserahkan kepada pemilik toko.

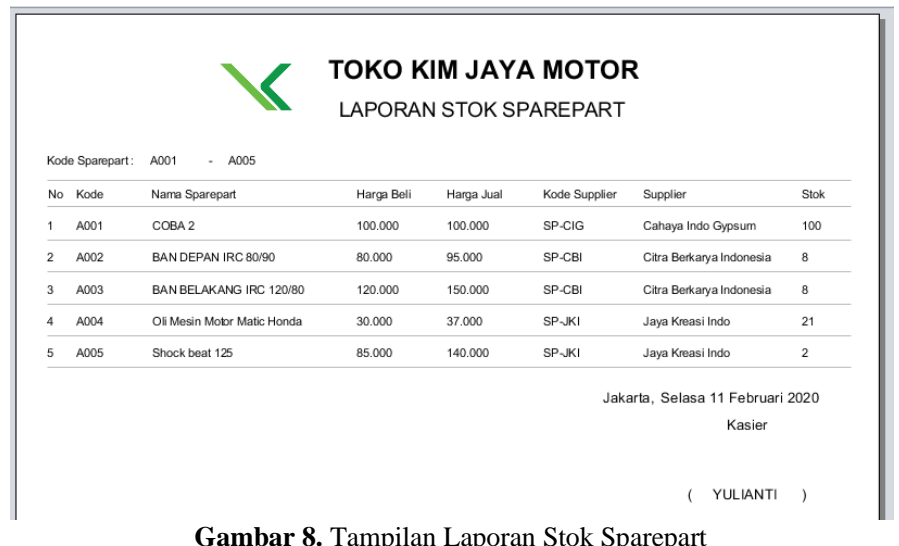

Gambar 8. Tampilan Laporan Stok Sparepart 
Laporan data stok sparepart ini didapat dari data-data pembelian dan penjualan yang sudah diinput admin ke dalam database yang nantinya diserahkan kepada pemilik toko.

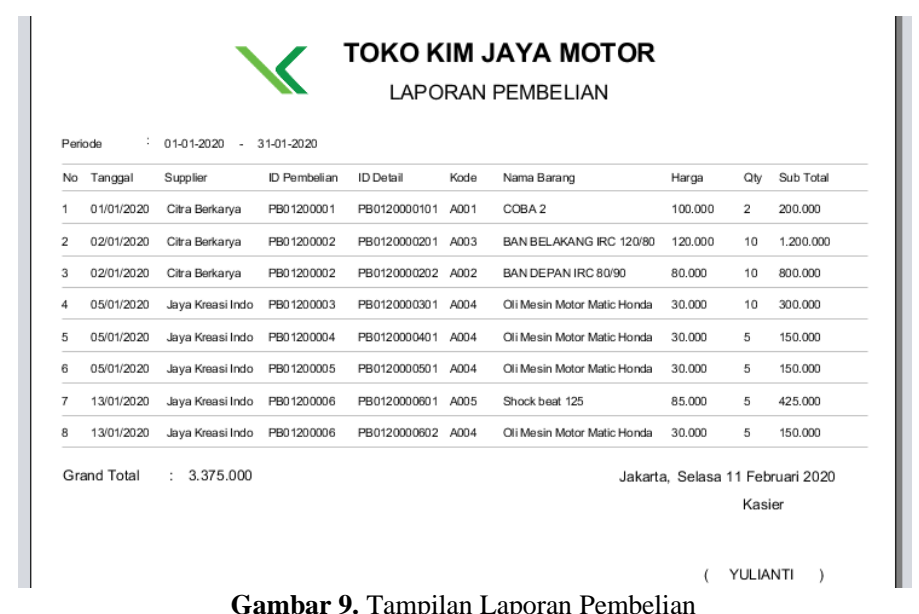

Laporan pembelian ini didapat dari data-data pembelian yang sudah diinput admin ke dalam database yang nantinya diserahkan kepada pemilik toko.

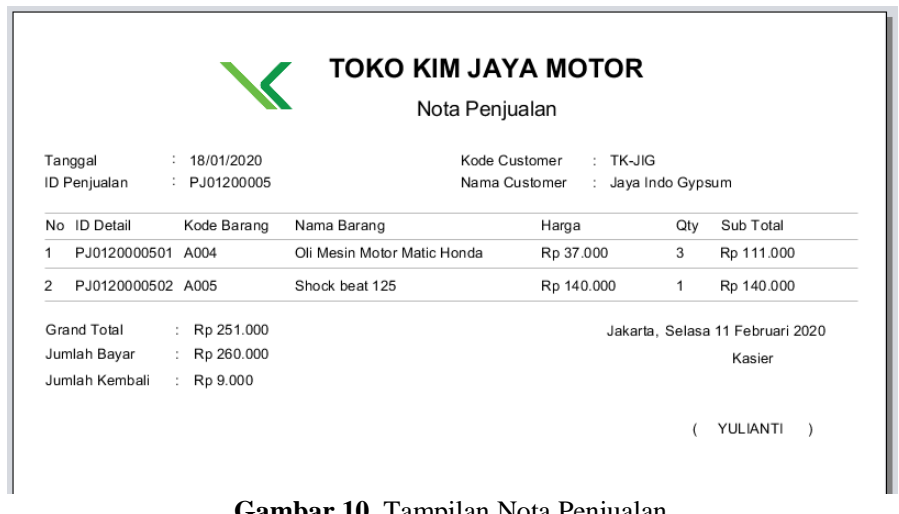

Gambar 10. Tampilan Nota Penjualan

Nota penjualan ini didapat dari transaksi penjualan yang sudah diinput admin berdasarkan barang permintaan customer dan sebagai bukti penjualan.

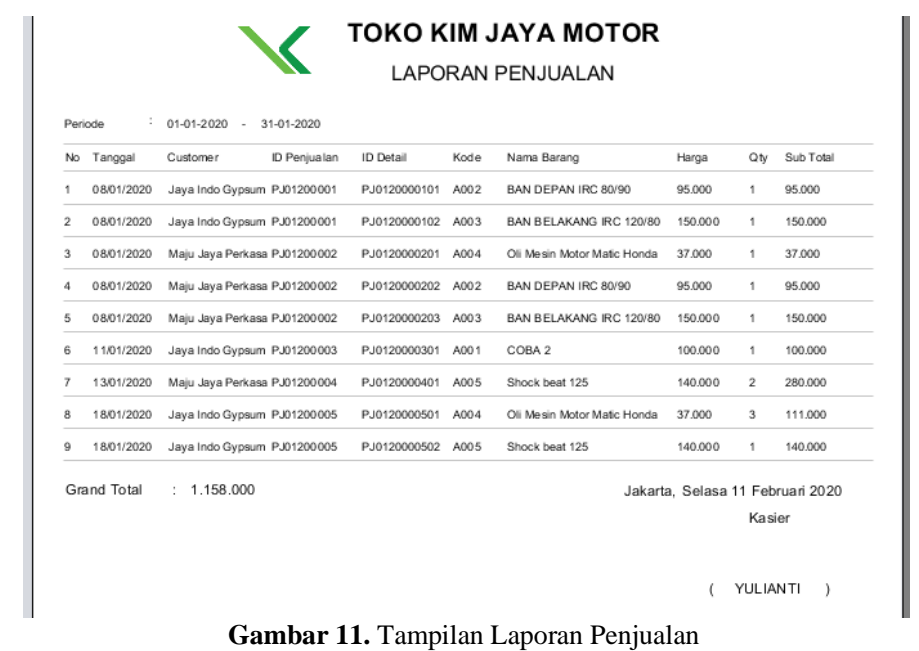

Laporan penjualan ini didapat dari data-data penjualan yang sudah diinput admin ke dalam database yang nantinya diserahkan kepada pemilik toko. 


\section{SIMPULAN}

Setelah melakukan analisa dan pengamatan maka peneliti menarik kesimpulan dengan menggunakan sistem komputerisasi maka Toko Kim Jaya Motor akan mengalami peningkatan dalam menangani proses seluruh data terutama data penjualan dibandingkan sistem manual, pengolahan data penjualan sparepart komputer pada Toko Kim Jaya Motor lebih efektif serta keamanan terhadap data lebih terjamin, proses dalam pembuatan laporan dapat dilakukan dengan cepat dan akurat, memudahkan administrator untuk memantau atau mengontrol data yang ada dalam database.

\section{DAFTAR PUSTAKA}

Ananto, W. D. dkk. (2013). Pembangunan Sistem Informasi Penjualan Pada Toko Ikhtyar Audio Pacitan. IJNS Indonesian Journal on Networking and Security. https://doi.org/ttp://dx.doi.org/10.1123/ijns.v4i3.100 Kadir, Abdul. (2014). Pengenalan Sistem Informasi Edisi Revisi. In Edisi Revisi.

Sukamto, R. A., \& Shalahudin, M. (2014). Rekayasa Perangkat Lunak Terstruktur dan Berorientasi Objek. Bandung. Sutabri, T. (2012). Konsep Sistem Informasi. Jurnal Administrasi Pendidikan UPI. 